\title{
O ENVELHECIMENTO NO CONTEXTO DA ODONTOLOGIA
}

\author{
THE AGING IN THE CONTEXT OF THE DENTISTRY
}

\author{
Ana Carolina de Assis Simões ${ }^{1}$ \\ Raquel Sylvia de Oliveira ${ }^{2}$ \\ Denise Maciel Carvalho ${ }^{3}$
}

\begin{abstract}
Resumo: Este trabalho teve como objetivo conhecer a realidade da saúde bucal do idoso e alguns de seus fatores determinantes. Para isso foi realizada uma revisão de literatura abordando a temática envelhecimento no contexto da odontologia. Os resultados apontaram que a população idosa é o segmento populacional que mais cresce. A saúde bucal na terceira idade é um fator indispensável para o envelhecimento saudável. Os problemas bucais mais prevalentes nessa faixa etária são as cáries radiculares e a doença periodontal, que contribuem para a grande maioria das extrações dentárias. Assim, faz-se necessário um trabalho continuado de orientação para o cuidado da saúde bucal do idoso, incluindo desde instruções para a limpeza diária dos dentes e próteses, até o controle da dieta e uso do flúor como fonte de fortalecimento da superfície dentária. É também fundamental a ampliação do estudo nessa área, visando qualificar a atenção e o tratamento odontológico para esses indivíduos.
\end{abstract}

Palavras-chave: Envelhecimento. Odontologia. Idoso. Saúde bucal.

Abstract: This work aimed at knowing the reality of old people oral health and some of its decisive factors. For that, a literature survey was accomplished approaching the theme aging in the context of dentistry. The results pointed that the senior population is the population segment that more grows. Oral health in the third age is an indispensable factor for the healthy aging. The more common oral problems in that age group are decays and disease, which contribute to most dental extractions. Thus, it is necessary to do a continuous work of orientation for care of old people oral health, including instructions for daily teeth cleaning and prostheses and the control of diet and use of the Fluor as a source of invigoration of dental surfaces. It is also fundamental to broaden studies in that area, seeking to qualify odontological assistance and treatment for those individuals.

Keywords: Aging. Dentistry. Old people. Oral health.

\footnotetext{
${ }^{1}$ Cirurgiã-dentista. E-mail:aninhassim@yahoo.com.br

${ }^{2}$ Cirurgiã-dentista

${ }^{3}$ Cirurgiã-Dentista: Especialista em Saúde Pública e em Odontologia em Saúde Coletiva. Mestre em Saúde Pública pela EERP/USP-Ribeirão Preto (SP).
} 


\section{Introdução}

Ao longo dos anos acompanhamos uma evolução dos conceitos de saúde e bem-estar, de prevenção de doenças e promoção da saúde, além de um despertar para maior conscientização da importância dos cuidados com a boca e com os dentes em todas as fases da vida.

Sabe-se que o Brasil, semelhante aos diversos países do mundo, está envelhecendo rapidamente. A população idosa, aqueles indivíduos com mais de 60 anos de idade, compõe atualmente o segmento populacional que mais cresce em termos proporcionais (CORMACK, 2007).

Os problemas de saúde modificam-se com o decorrer dos anos. O envelhecimento causa várias alterações fisiológicas em todo o organismo, havendo uma grande prevalência de doenças crônicas nestes indivíduos, que constituem a maior parcela de pessoas que necessitam de atendimento nos serviços de saúde (SILVA; SAINTRAIN, 2006).

A odontologia reuniu um corpo de doutrina importante relativo aos efeitos do tempo sobre a boca, dentes e estruturas anexas. Nasceu assim a Odontogeriatria, que no Brasil, vem sendo enfocada com seriedade e muito acima dos interesses pessoais dos envolvidos, visando o bem estar do idoso brasileiro, um ser geralmente oprimido por aposentadorias escorchantes e vivendo em cidades não preparadas para acolhê-los (BRUNETTI; MONTENEGRO, 2002; p 57).

A saúde bucal na terceira idade é um fator indispensável para o envelhecimento saudável e uma boa qualidade de vida, mas sua importância ainda não é devidamente reconhecida.

A perda total dos dentes (edentulismo) é aceita como um fenômeno natural do envelhecimento. No entanto, sabe-se hoje que esse fato é o reflexo da falta de prevenção, de informação e consequentemente de cuidados com a higiene bucal, que deveriam ser destinados principalmente à população adulta, para que mantenha seus dentes até idades mais avançadas (COLUSSI; FREITAS, 2002).

A doença periodontal aumenta com o decorrer da idade, e tem sido vista como a principal causa do edentulismo, que resulta num grande número de indivíduos necessitando de próteses (CORMACK, 2007). 
Outra razão para a perda dental é a evolução lenta de cáries radiculares, infiltrações e cáries sob restaurações e próteses, assim como fraturas que normalmente ocorrem pela má distribuição das forças mastigatórias. (VARELLIS, 2005, p 324).

Sendo assim, Pucca Jr. (2002, p. 307) explica que este quadro precário é decorrente não só do processo de envelhecimento por si, mas principalmente de um conjunto de agravos diferenciados que atingem os idosos de maneiras distintas durante a vida.

Nesse contexto, conhecer a realidade da saúde bucal do idoso e alguns de seus fatores determinantes constitui-se na motivação para este estudo, que pretende mostrar uma visão abrangente do envelhecimento e das modificações da saúde bucal em razão do decorrer da idade.

O objetivo do trabalho é verificar através da produção científica nacional, as principais alterações manifestadas nas estruturas bucais decorrentes do envelhecimento.

\section{Metodologia}

Para o presente trabalho optou-se por uma revisão de literatura realizando um levantamento bibliográfico no acervo da Biblioteca da Universidade de Uberaba e em publicações on-line.

Foram utilizadas para a busca as seguintes palavras-chaves: saúde bucal, idoso, envelhecimento, epidemiologia. A pesquisa não foi limitada a nenhum período específico.

Ao final do levantamento, os artigos encontrados foram analisados de acordo com o critério de inclusão estabelecido, ou seja, abordar a temática: o envelhecimento no contexto da odontologia. 


\section{O envelhecimento e os aspectos bucais}

Com o aumento da população de idosos é cada vez mais necessário ter uma demanda crescente e diversificada para a atenção e para o tratamento odontológico desses indivíduos.

Em estudo realizado por Cormack (2007), buscou-se uma interação das questões relativas à odontologia ao contexto dos estudos geriátricos e gerontológicos, onde o processo do envelhecimento se relacione com a manutenção da saúde oral. Através de uma revisão da literatura foram apresentados alguns dados relativos ao crescimento da população idosa e a mudança do perfil epidemiológico do "novo idoso" que surge, com diferentes necessidades orais em relação à geração anterior, tais como a diminuição do edentulismo, o aumento das cáries das superfícies radiculares e o incremento da doença periodontal. Concluiu-se que com o aumento da população idosa, teremos nos próximos anos uma demanda por uma maior e mais diversificada atenção odontológica para esse grupo em particular. A profissão odontológica - incluindo associações de classe, o meio universitário e os diversos prestadores de serviço - devem estar cientes e alertas para essa questão, de forma a ampliar o estudo e a pesquisa nessa área.

Brunetti e Montenegro (2002, p.322), aprimorando os estudos do envelhecimento, diante de uma revisão de literatura constataram um aumento significativo no número de pacientes de terceira idade. Observaram existir um número de profissionais insuficientes e com pouco preparo para o atendimento destes indivíduos em nosso país, realçando a necessidade de profundos estudos e adequação técnica para atuarem nesta população. Concluíram que a Odontologia irá dedicar-se cada vez mais ao atendimento de idosos, que devido às suas maiores perspectivas de vida, passa a ser um promissor mercado de trabalho para classe odontológica, mas que exige uma grande motivação no estudo das particularidades desta faixa etária.

Araújo et al. (2006), em uma revisão de literatura dissertaram sobre crescente envelhecimento da população mundial, inclusive no Brasil, ressaltando a importância de medidas para se lidar com esta situação. No Brasil, a maioria dos idosos é do sexo feminino; vive em domicílios multigeracionais; é referência econômica nos mesmos; possui baixo nível socioeconômico; portadora de, pelo 
menos, uma doença crônica; independente para realização das atividades da vida diária; não possui dentes, e busca atenção em saúde no SUS. Os idosos brasileiros expostos a situações de vulnerabilidade social estão sujeitos à interferência direta dos determinantes sociais no processo saúde-doença. O Suporte Social inclui políticas e redes de apoio social, que atuam como agente de integração do idoso na sociedade, minimizando os riscos de exclusão social e, conseqüentemente, de danos à sua saúde por meio de medidas de Promoção de Saúde. Este artigo aborda o Suporte Social e alguns de seus aspectos, tais como: tipo e local de residência, transporte e suporte financeiro; em idosos brasileiros e sua relação com a Promoção de Saúde.

Geralmente os pacientes geriátricos apresentam um quadro clínico comum. O cuidado geriátrico inclui pelo menos o diagnóstico, prevenção e tratamento da cárie, doenças periodontais, dores de cabeça e pescoço, disfunções salivares, problemas com a prótese e comprometimento das funções de mastigação, deglutição e paladar. (FIAMINGHI et al., 2004)

Meneghim et al. (2002), verificaram as condições periodontais e lesões radiculares, de uma amostra de população idosa, institucionalizada do município de Piracicaba - SP. Nesse estudo, foram examinados 151 idosos com idade entre $54 \mathrm{e}$ 93 anos. Os sextantes foram examinados e classificados do ponto de vista de saúde periodontal, necessidade de tratamento periodontal, presença de retração gengival e lesões radiculares, utilizando-se como critérios os indicadores da OMS (1999). Comparando-se duas faixas etárias: de pacientes com idade entre 50 e 75 anos e pacientes com idade acima de 75 anos, constatou-se que há um aumento na prevalência de lesões de cárie e outras afecções radiculares, como erosão e abrasão, indicando aumento na susceptibilidade a tais lesões com o passar da idade.

Moreira et al. (2005), objetivaram realizar uma revisão sistemática da literatura, no período de 1986 a 2004, por meio de busca em bases de dados, sobre os problemas bucais mais prevalentes entre os idosos brasileiros e conhecer os principais obstáculos no acesso aos serviços de saúde. Os valores médios do índice CPO-D encontrados nos artigos pesquisados foram de 25 a 31 . Verificou-se grande porcentagem de indivíduos edêntulos. As principais barreiras quanto ao acesso aos serviços odontológicos foram a baixa escolaridade, a baixa renda e a escassa oferta 
de serviços públicos de atenção à saúde bucal. Diante desses fatores, a saúde bucal do idoso brasileiro encontra-se em situação precária, com elevados índices de edentulismo, refletindo a ineficácia historicamente presente nos serviços públicos de atenção odontológica, limitando a extrações em série e serviços de urgência, baseados no modelo curativista.

Colussi e Freitas (2002), fizeram uma revisão crítica dos estudos epidemiológicos apresentados nas publicações nacionais com relação à saúde bucal do idoso. Pesquisaram todos os artigos indexados nas bases de dados BBO, LILACS e MEDLINE, a partir de 1988, data da publicação do Levantamento Epidemiológico Nacional. Foram encontrados 29 artigos, dos quais sete estudos foram analisados quanto à metodologia utilizada (faixa etária, tipo de amostra, forma de apresentação dos dados) e quanto aos resultados apresentados (índice CPOD, participação de dentes extraídos, percentual de edêntulos e, uso e necessidade de prótese). O CPOD encontrado variou de 26,8 a 31,0 , sendo que o componente extraído representou cerca de $84 \%$ desse índice. A prevalência do edentulismo ficou em $68 \%$. Somente 3,9\%, um pequeno percentual dos idosos não necessita nem usa qualquer tipo de prótese, e o uso da prótese total é mais freqüente no arco superior do que no inferior. A falta de padronização na organização e apresentação dos dados, assim como a sua escassez, prejudicou a análise, sugerindo que deva haver uma maior preocupação por parte dos pesquisadores quanto à realização de novas pesquisas, e principalmente, quanto à maneira como estas serão conduzidas. Apesar disso, confirmaram-se as condições muito precárias de saúde bucal do Brasil.

Rosa et al. (1992), em um levantamento epidemiológico, realizado em São Paulo, utilizando dois grupos de idosos, de 60 anos ou mais (examinados em domicílio e instituições beneficentes), mostram que a população de terceira idade apresenta condições muito precárias de saúde bucal. O índice CPO variou entre 23 a 31. Mostrando que em média cada idoso possui apenas dois dentes sadios. Aproximadamente $75 \%$ eram edêntulos e apenas $50 \%$ eram portadores de prótese total. Bolsas periodontais predominaram em relação as demais patologias em $65 \%$ dos idosos. Este quadro demonstra que a cárie e a doença periodontal contribuem para mais de $90 \%$ das extrações dentárias. 
Silva e Fernandes (2001), avaliaram a percepção da condição bucal em idosos, pela aplicação de questionário com perguntas voltadas para a auto-avaliação da situação bucal, e analisaram os fatores clínicos, subjetivos e sociodemográficos que interferem nessa percepção. Participaram do estudo 201 pessoas, dentadas, com 60 anos ou mais, funcionalmente independentes, que freqüentavam um centro de saúde localizado em Araraquara, SP, Brasil. Foi aplicado o questionário. Realizaram exame clínico para determinar a prevalência das principais doenças bucais. Usaram testes estatísticos para determinar a associação das variáveis. $O$ exame clínico revelou grande prevalência das principais doenças bucais, apesar de $42,7 \%$ das pessoas avaliarem sua condição bucal como regular. As variáveis associadas às auto-avaliações foram: classe social, índice de GOHAl, dentes cariados e indicadores de extração. A análise multivariada mostrou que os preditores da auto-avaliação foram o GOHAl, os dentes com extração indicada e o índice Community Periodontal Index and Treatment Needs. Esses preditores explicaram $30 \%$ da variabilidade da auto-avaliação. Concluíram assim que a percepção da saúde bucal teve pouca influência nas condições clínicas, mostrando ser necessário desenvolver ações preventivas e educativas para a população.

Os métodos preventivos não são apenas imprescindíveis como também constituem-se como eixo de qualquer intervenção que vise à saúde bucal na terceira idade. (PUCCA JR, 2002, p.299)

Veras e Caldas (2004), em seu estudo abordaram o movimento Universidades da Terceira Idade que vem experimentando incremento substancial desde os anos 70, difundindo conceitos e experiências práticas que representam uma nova forma de promover a saúde da pessoa que envelhece, a partir de uma ação interdisciplinar comprometida com a inserção do idoso como cidadão ativo na sociedade. O movimento visa contribuir para a promoção da saúde física, mental e social das pessoas idosas, lançando mão das possibilidades existentes nas universidades. No Brasil, existem pelo menos 150 programas dessa natureza. Os resultados vêm sendo sistematizados e debatidos, trazendo novas perspectivas de inserção e ampliação da participação social e de melhoria das condições de saúde, e qualidade de vida dos seus participantes. O artigo discute a importância do movimento como estratégia para a melhoria da qualidade de vida da população idosa. A partir da contextualização do movimento no mundo e no Brasil, uma 
experiência desenvolvida na Universidade do Estado do Rio de Janeiro (UERJ), desde 1993 é descrita e analisada. Tendo como pressupostos básicos a interdisciplinaridade, a participação social e a promoção da saúde, a proposta da UERJ utiliza metodologia adaptada às especificidades desta clientela no desenho de um programa amplo de atenção integral à saúde do idoso.

Para Pucca Jr. (2002, p.299), os recursos básicos para orientação do idoso envolvem informações quanto à limpeza regular diária dos dentes e próteses, quanto ao controle da dieta e orientações visando o fortalecimento da superfície dentária, com o uso do flúor.

Segundo Varellis (2005, p.127), para controle da cárie e da doença periodontal são usadas medidas preventivas, como controle da placa bacteriana, avaliação e estimulação da função mastigatória, fluorterapia, estimuladores de saliva, aconselhamento dietético entre outros.

\section{Considerações Finais}

Tanto as fontes revisadas, quanto a literatura que serviu de base para a realização deste estudo, apontam para uma questão fundamental: a população idosa é o segmento populacional que mais cresce. Assim, a profissão odontológica, incluindo suas associações, deve estar ciente e alerta para essa questão, de forma a ampliar o estudo e a pesquisa nessa área, visando qualificar a atenção e o tratamento odontológico para esses indivíduos.

A saúde bucal na terceira idade é um fator indispensável para o envelhecimento saudável e uma boa qualidade de vida. Entretanto, as condições desiguais em que as pessoas vivem e trabalham são refletidas nitidamente na saúde bucal, uma vez que idosos expostos a situações de vulnerabilidade social estão mais sujeitos à interferência direta dos determinantes sociais no processo saúdedoença.

Os problemas bucais mais prevalentes nessa faixa etária são as cáries radiculares e a doença periodontal, que contribuem para a grande maioria das extrações dentárias. Embora o edentulismo seja considerado por muitos um 
fenômeno natural do envelhecimento, podemos entender que este é o reflexo da falta de orientação e de cuidados com a saúde bucal em todas as idades.

Uma das estratégias para mudar essa realidade que prevalece atualmente é trabalhar preventivamente de forma que as pessoas possam chegar à idade mais avançada com uma dentição ainda saudável. E, para aqueles que já perderam seus dentes, deve-se assegurar o acesso à reabilitação das funções mastigatórias e estéticas, através da confecção de próteses dentárias. Além disso, faz-se necessário um trabalho continuado de orientação para o cuidado com a sua própria saúde bucal, incluindo desde instruções para a limpeza diária dos dentes e próteses, até o controle da dieta e uso do flúor como fonte de fortalecimento da superfície dentária.

\section{REFERÊNCIAS}

ARAÚJO, S.S.C. et al. Suporte social, promoção de saúde e saúde bucal na população idosa no Brasil. Interface - Comunicação, Saúde, Educação, Brasil, v.10, n.19, p.203-16, jan./jun. 2006.

BRUNETTI, R.; MONTENEGRO, F. Odontogeriatria: noções de interesse clínico. São Paulo: Artes Médicas, 481p. 2002

COLUSSI, C. F.; FREITAS, S. F. T. Aspectos epidemiológicos da saúde bucal do idoso no Brasil. Caderno de Saúde Pública, Brasil, v.18, n.5, p.1313-20, set./out. 2002.

CORMACK, E.F. A saúde oral do idoso. Disponível em: http://www.odontologia.com. br/artigos/geriatria.html. Acesso em 10/09/2007.

FIAMINGHI, D.L. et al. Odontogeriatria: a importância da autoestima na qualidade de vida do idoso. Rev. de Clín. Pesq. Odontol., Brasil, v.1, n.2, p.37-40, out./dez.2004.

MENEGHIM, M. de C.; PEREIRA, A. C.; SILVA, F. R. B. Prevalência de cárie radicular e condição periodontal em uma população idosa institucionalizada de Piracicaba - SP. Pés. Odont. Brás., Brasil, v.16, n. 1, p. 50-56, jan./mar.2002.

MOREIRA, R.S. et al. A saúde bucal do idoso brasileiro: revisão sistemática sobre o quadro epidemiológico e acesso aos serviços de saúde bucal. Caderno de Saúde Pública, Brasil, v.21, n.6, p.1665-75, nov./dez.2005.

PUCCA JR., G.A. Saúde Bucal do Idoso: Aspectos Sociais e Preventivos. In: PAPALEO NETTO, M. Gerontologia: a velhice e o envelhecimento em versão globalizada. São Paulo: Atheneu, cap. 4, p. 297 - 310. 2002

ROSA, A.G.F. et al. Condições de saúde bucal em pessoas de 60 anos ou mais no Município de São Paulo (Brasil). Revista de Saúde Pública, Brasil, v.26, p.155-160, jun./1992. 
SILVA, A.L.; SAINTRAIN, M.V.L. Interferência do perfil epidemiológico do idoso na atenção odontológica. Revista Brasileira de Epidemiologia. Brasil, v.9, n.2, p.24250, abr.2006.

SILVA, S.R.C.; FERNANDES, R.A.C. Autopercepção das condições de saúde bucal por idosos. Revista de Saúde Pública. Brasil, v.35, n.4, p.349-55, abr.2001.

VARELLIS, M.L.Z. O paciente com necessidades especiais na Odontologia. São Paulo: Santos, 510p. 2005

VERAS, R.P. et al. Promovendo a saúde e a cidadania do idoso: o movimento das universidades da terceira idade. Ciência e Saúde coletiva, Brasil, v.9, n.2, p.42332, abr./jun.2004.

Recebido para publicação em: 20/04/09

Aceito: 30/07/09 